\title{
Serial monitoring of LV function following chemotherapy: assessment using advanced echocardiography and cardiovascular magnetic resonance
}

\author{
Suchi Grover ${ }^{1,3^{*}}$, Rebecca Perry ${ }^{1,2}$, Darryl Leong ${ }^{1}$, Majo Joseph², Bogda Koczwara ${ }^{4}$, Joseph Selvanayagam,3 \\ From 17th Annual SCMR Scientific Sessions \\ New Orleans, LA, USA. 16-19 January 2014
}

\section{Background}

Patients receiving anthracyclines (A) and herceptin $(\mathrm{H})$ for treatment of breast cancer require serial monitoring of LV function. Although CMR is considered the gold standard for assessment of volumes and function, most tertiary institutions rely on echocardiography or gated heart pool scans. 2D transthoracic echocardiographic (TTE) image quality relies on appropriate acoustic windows, and accuracy and reproducibility may be particularly limited in this population due to mastectomy and scar. We sought to assess the utility of TTE (LVEF and GLS) compared to CMR in the diagnosis of Stage B heart failure (defined as evidence of structural disease but without signs and symptoms of heart failure [1]) in breast cancer patients receiving cytotoxic chemotherapy.

\section{Methods}

In total, 44 patients (30 receiving $\mathrm{A}$ and 14 receiving $\mathrm{T}$ ) underwent cardiac magnetic resonance (CMR) for $L V$ function and advanced 2D echocardiography for LV function and global longitudinal strain (GLS) at 3 timepoints (baseline, 3 months and 12 months). We defined stage B heart failure as LVEF $<10 \%$ from baseline, and/ or LVEF below $55 \%$ and/or GLS < -19.7[2].

\section{Results}

CMR cine assessment of LV function was performed in all 44 patients $(100 \%)$. Thirty percent (13/44) could not have accurate echocardiographic EF assessment performed at 1 or more time points. Early LV dysfunction was detected by CMR following commencement of chemotherapy (table). There was poor correlation between CMR LVEF and echocardiography EF (graph) with wide limits of agreement (-23.526 to $13.015 \%)$. At 12 months, 8 patients (18\%) demonstrated stage B heart failure, however none were below the lower limits of normal $(>55 \%)$. None of these showed a significant change in TTE EF, however 2 of these patients had GLS $<19.7$ at 12 months.

\section{Conclusions}

A significant number (approx. 1/3) of breast cancer patients are unable to have adequate LV function assessment by echocardiography. Subtle LV dysfunction may be a precursor to overt cardiomyopathy and is currently not adequately diagnosed by echocardiography even with inclusion of 2D global longitudinal strain. Serial monitoring of LV function using a non-radiation imaging technique is best performed by CMR.

\section{Funding}

None.

Table 1

\begin{tabular}{|c|c|c|c|}
\hline & $\begin{array}{c}\text { LVEF (CMR) } \\
\%\end{array}$ & $\begin{array}{c}\text { LVEF } \\
\text { (Echo) } \\
\text { (\%) }\end{array}$ & GLS \\
\hline Baseline & $71.9 \pm 6.3$ & $63.8 \pm 5.7$ & $-21.4 \pm 2.6$ \\
\hline 3 months & $66.7 \pm 6.7^{* *}$ & $63.5 \pm 7.2$ & $-19.5 \pm 2.0 * *$ \\
\hline 12 months & $65.9 \pm 7.0$ ** & $62.1 \pm .9$ & $-20.1 \pm 2.6$ \\
\hline
\end{tabular}

${ }^{1}$ Flinders University, Adelaide, South Australia, Australia

Full list of author information is available at the end of the article 


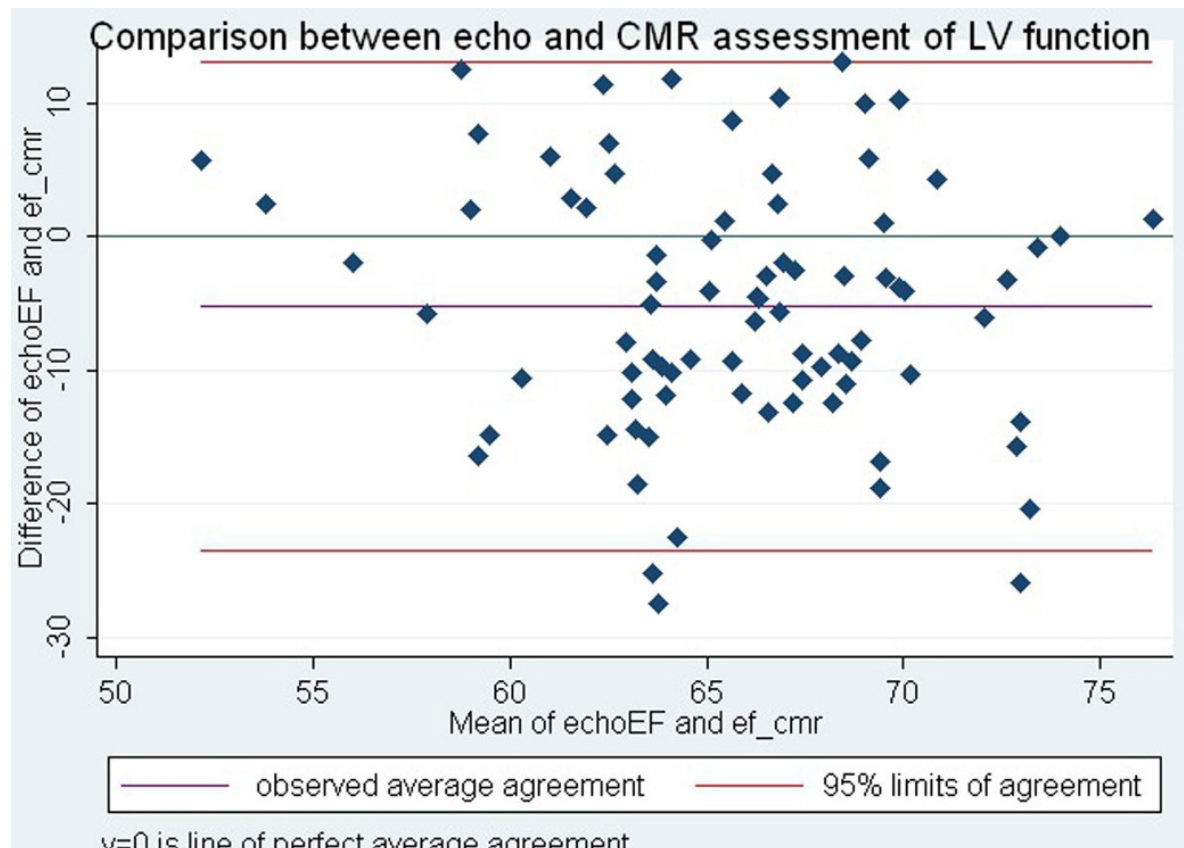

$y=0$ is line of perfect average agreement

Figure 1

\section{Authors' details}

${ }^{1}$ Flinders University, Adelaide, South Australia, Australia. ${ }^{2}$ Cardiology, Flinders Medical Centre, Adelaide, South Australia, Australia. ${ }^{3}$ Flinders Cardiac

Cardiovascular Magnetic Resonance, Flinders Medical Centre, Adelaide, South Australia, Australia. ${ }^{4}$ Medical Oncology, Flinders Centre for Innovation in Cancer, Adelaide, South Australia, Australia.

Published: 16 January 2014

\section{References}

1. Hunt SA, Abraham WT, Chin MH, Feldman AM, Francis GS, Ganiats TG, et al: 2009 focused update incorporated into the ACC/AHA 2005 Guidelines for the Diagnosis and Management of Heart Failure in Adults: a report of the American College of Cardiology Foundation/American Heart Association Task Force on Practice Guidelines: developed in collaboration with the International Society for Heart and Lung Transplantation. Circulation 2009, 119(14):e391-479.

2. Yingchoncharoen T, Agarwal S, Popovic ZB, Marwick TH: Normal ranges of left ventricular strain: a meta-analysis. J Am Soc Echocardiogr 2013, 26(2):185-91.

doi:10.1186/1532-429X-16-S1-P139

Cite this article as: Grover et al: Serial monitoring of LV function following chemotherapy: assessment using advanced echocardiography and cardiovascular magnetic resonance. Journal of Cardiovascular Magnetic Resonance 2014 16(Suppl 1):P139.

Submit your next manuscript to BioMed Central and take full advantage of:

- Convenient online submission

- Thorough peer review

- No space constraints or color figure charges

- Immediate publication on acceptance

- Inclusion in PubMed, CAS, Scopus and Google Scholar

- Research which is freely available for redistribution 